\title{
Vascular Anatomy of the Hamster Retractor Muscle with Regard to Its Microvascular Transfer
}

\author{
M.C.J. de With ${ }^{a}$ A.M. de Vries ${ }^{a} \quad$ A.B.A. Kroese ${ }^{\text {b, d }}$ E.P.A.B. van der Heijden ${ }^{a}$ \\ R.L.A.W. Bleys ${ }^{c}$ S.S. Segal ${ }^{\mathrm{e}}$ M. Kon ${ }^{\mathrm{a}}$
}

Departments of a Plastic Reconstructive and Hand Surgery, ${ }^{\text {b Surgery and }}{ }^{\mathrm{C} P h a r m a c o l o g y}$ and Anatomy, University Medical Center Utrecht, ${ }^{d}$ Institute for Risk Assessment Sciences, Utrecht University, Utrecht, The Netherlands; ${ }^{e}$ Department of Medical Pharmacology and Physiology and Dalton Cardiovascular Research Center, University of Missouri - Columbia, Columbia, Mo., USA

\section{Key Words}

Animal model $\cdot$ Experimental model $\cdot$ Skeletal muscle $\cdot$ Transplantation • Vascularization $\cdot$ Microsurgery $\cdot$ Ischemia and reperfusion

\begin{abstract}
Background: The hamster retractor muscle (RET) is used as an in vivo model in studies of skeletal muscle ischemia-reperfusion injury. The RET is unique in that the muscle can be isolated while preserving the primary vascular supply so that its contractile function can be measured simultaneously with local microvascular responses to experimental interventions. The goal of this study was to understand the anatomical origin of the vascular supply to the RET and determine whether the RET can be used as a free flap after surgical isolation of the thoracodorsal vessels. Methods: Microdissection was performed to determine the anatomy of the vasculature that supplies and drains the RET. Results: Distinct numbers and patterns of feed arteries (2-4) and collecting veins (1-3) were identified ( $n=26$ animals). Dye injection $(n=8)$ of the thoracodorsal artery demonstrated that the RET remains perfused following its isolation on the thoraco-
\end{abstract}

dorsal pedicle. Heterotopic allograft transplantation of the RET $(n=2)$ was performed by anastomosing the thoracodorsal vessels to the femoral vessels using the end-to-side technique. Conclusions: The anatomical relationships indicate that the RET can be used as a free flap model for evaluating the effect of preservation strategies and transplantation on skeletal muscle microcirculation and contractile function.

Copyright $\odot 2008$ S. Karger AG, Basel

\section{Introduction}

The hamster cheek pouch retractor (RET) muscle is a long, thin strap-shaped muscle, running from the lumbodorsal fascia and last three thoracic vertebrae to the cheek pouch [1]. The RET serves as an antagonist to the longitudinal musculature of the cheek pouch wall and retains the cheek pouch above the scapula when it is filled with material as well as prevents eversion of the pouch when its contents are ejected [1]. Its superficial location and unique anatomical organization have enabled the muscle to be used for intravital studies of oxygen transport [2] and blood flow regulation [3-5] in the microcir-

\section{KARGER}

Fax +4161306 1234 E-Mail karger@karger.ch www.karger.com
(C) 2008 S. Karger AG, Base

0014-312X/09/0422-0097\$26.00/0

Accessible online at:

www.karger.com/esr
Miriam C.J. de With, MD

Department of Plastic Reconstructive and Hand Surgery

University Medical Center, G04.122

Heidelberglaan 100, NL-3584 CX Utrecht (The Netherlands)

Tel. +31 88755 6897, Fax +31 30251 6097, E-Mail dewith@nvpc.nl 
culation of mammalian skeletal muscle. The central region of the RET muscle is supplied by posterior retractor 'feed' arteries, which arise from the thoracodorsal artery, a branch of the subscapular artery $[1,6,7]$. These feed arteries vary in number, are accompanied by 'collecting veins', and anastomose with each other at the arteriolar level via arcading segments $[4,6,7]$. The RET is unique in that the muscle can be exteriorized while preserving its primary vascular supply [8], enabling muscle force production to be monitored concomitant with the study of microvascular responses at defined locations within the peripheral circulation $[5,9]$. This preparation has thereby provided novel insight into the regulation of skeletal muscle blood flow [for reviews, see 10, 11].

Feed arteries originate proximally from a larger conduit artery (e.g. thoracodorsal artery in the RET) and provide substantial resistance to blood flow before giving rise to the arterioles within the muscle $[10,12]$. In response to contractile activity, vasodilator signals 'ascend' from the microcirculation to encompass the feed arteries upstream $[9,10]$ and thereby enable these proximal vessels to serve a key role in regulating blood flow delivery into intermediate and terminal arteriolar networks, which control the distribution and magnitude of blood flow to skeletal muscle fibers $[10,12]$. In feed arteries of the RET, the endothelium serves as the cellular pathway for conducting the vasodilator response along the vessel wall and into the surrounding smooth muscle cells to produce relaxation [13]. Accordingly, direct observation of conducted vasodilation along RET feed arteries following an ischemia-reperfusion (I-R) insult is integral to assessing endothelial dysfunction [14].

The effect of transplantation on the microcirculation of skeletal muscle is poorly understood, in large part due to the lack of a suitable experimental model. Recently, we reported that both contractile function and endothelium-dependent blood flow regulation of the RET were impaired by I-R [14]. These findings suggested that the RET may prove useful as a free flap model to evaluate the efficacy of preservation strategies aimed to protect skeletal muscle and its vascular supply during cold preservation and reperfusion [15-17]. With the goal of providing further insight into how transplantation affects microvascular integrity, the aim of the present study was to understand the anatomical origin of the vascular supply to the RET and determine whether it can be isolated on a thoracodorsal vascular pedicle, preserving the feed arteries and collecting veins. Because restoration of flow is essential to the survival of a free flap, we assessed the vascular territory within the RET that was actually perfused by the feed arteries. Further, the most suitable site for performing microsurgical anastomoses was determined, which requires vessel diameter of at least $\sim 300 \mu \mathrm{m}$ [18].

\section{Materials and Methods}

\section{Animal Care}

Male golden hamsters (Harlan-Winkelmann, Borchen, Germany), weighing $120 \pm 3 \mathrm{~g}$, were housed in groups of 3-4 animals on a $12 / 12$-hour (light/dark) cycle at $23-24^{\circ} \mathrm{C}$ and provided with standard diet food and water ad libitum. The animals received care in compliance with the European Convention guidelines (86/609/EC). All procedures were approved by the Utrecht University Committee for Experiments on Animals. Hamsters were injected with buprenorfinehydrochloride (Temgesic ${ }^{\circledR}$; ScheringPlough, Utrecht, The Netherlands) $5 \mathrm{mg} / \mathrm{kg}$ s.c. $30 \mathrm{~min}$ prior to surgery. Isoflurane ${ }^{\circledR}$ (Abbott Animal Health, Oudewater, The Netherlands), supplied through a ventilation mask, at $5 \%$ with $100 \%$ oxygen $(1 \mathrm{l} / \mathrm{min})$ was used to induce anesthesia $(\sim 5 \mathrm{~min})$. Isoflurane ${ }^{\circledR}$ at $2 \%$ with oxygen $(0.3 \mathrm{l} / \mathrm{min})$ and air $(0.6 \mathrm{l} / \mathrm{min})$ was subsequently used to maintain anesthesia. Excess vapor was scavenged by vacuum. Sterile saline was delivered through an intraperitoneal cannula (Abbocath-T 18 G; Abbott, Sligo, Ireland) to replace body fluids during the experiment $(1 \mathrm{ml} / \mathrm{h}$; Fresenius Orchestra; Fresenius Kabi, Utrecht, The Netherlands).

During the surgery for isolation of the RET on its vascular pedicle, body temperature was maintained at $37.0-38.0^{\circ} \mathrm{C}$ with heat conducted from a warm copper plate positioned beneath the hamster. The surgical field was irrigated continuously with preheated Ringer's lactate solution containing in $\mathrm{mmol} / \mathrm{l}: \mathrm{Na}^{+} 131$, $\mathrm{Ca}^{2+} 1.8, \mathrm{~K}^{+}$5.4, $\mathrm{Cl}^{-}$111, lactate 111, 273 mosm/l (Baxter, Utrecht, The Netherlands). At the end of the experiment, animals were killed by an intracardial overdose of sodium pentobarbital (Nembutal ${ }^{\circledR}$; CEVA Sante Animale BV, Maassluis, The Netherlands).

\section{Retractor Muscle and Vascular Dissection}

A hamster was positioned on its left side to isolate the RET on the right side. To expose the RET, a $\sim 3-4-\mathrm{cm}$ incision was made through the overlying skin, which was retracted to expose the underlying tissue. Using microdissection while viewing through a stereomicroscope (OPMI 6-DF; Zeiss, Jena, Germany), the muscle was cleared of connective tissue and visible nerve branches. Stainless steel wires (diameter $0.5 \mathrm{~mm}$ ) were sutured to the origin and insertion of the RET, exactly at the caudal margin of the cheek pouch, representing the rostral muscle end, and at the musculotendinous transition point at the lumbodorsal (caudal) end (see dotted lines in figure 1a). This was done to enhance muscle manipulation during surgery and prevent folding of muscles during the staining process (see Vascular Territory). The resting length of the muscle was measured between the stainless steel wires in situ.

The RET was then severed from its origin and insertion and reflected dorsally to visualize the feed arteries and collecting veins on its ventral surface. During this isolation, small vessels supplying the cranial and lumbodorsal ends of the muscle were cauterized and cut (shown in figure la and see Results). While carefully maintaining the integrity of the feed arteries and collecting veins at the ventral surface, the nerve branches, fat pads 
Fig. 1. Vascular anatomy of the hamster RET muscle. In the exposed RET in situ (a) the blood supply is indicated to be via three routes (1-3), of which the thoracodorsal (1) is the primary source. The feed arteries and collecting veins are indicated by 4 and cannot clearly be seen from this perspective of the dorsal surface. The two dotted lines represent the locations at which the rostral $\left(^{*}\right)$ and caudal $\left({ }^{* *}\right)$ margins of the RET were sutured to stainless steel wires and cut in order to flip the muscle over and reveal the vasculature in more detail from the ventral surface as illustrated in b-d. The feed arteries and collecting veins on the ventral surface of the RET are depicted in $\mathbf{b}$ and $\mathbf{c}$, where the most frequently encountered arterial and venous pedicle patterns are shown. The main thoracodorsal artery emerges from the axilla and runs between the teres major and latissimus dorsi muscles. It bifurcates at the level of the spinotrapezius muscle, giving off a branch running underneath the spinotrapezius muscle, which is defined as the 'deep' thoracodorsal artery. The other branch runs over the latissimus dorsi muscle and is defined as the 'superficial' thoracodorsal artery. The same nomenclature is used for the accompanying venous branches. In $\mathbf{b}$, three feed arteries branching off the thoracodorsal artery are accompanied by two collecting veins (35\% of total). Note that the most caudal artery does not have a paired collecting vein. In c, two feed arteries are each accompanied by a paired collecting vein (31\%). The darker colored arterial and venous segments in $\mathbf{b}$ and $\mathbf{c}$ indicate - in case of performing a free flap - the full extent of the vascular pedicles. The arrows point out the exact sites used for anastomosis. In c, a dual thoracodorsal vein is shown. The enlargement in $\mathbf{d}$ shows a detail of $\mathbf{b}$. The side branches of the most proximal feed artery and collecting vein supplying a part of the spinotrapezius muscle (present in $65 \%$ of preparations) are particularly difficult to dissect and ligate. $\mathrm{CP}=$ Cheek pouch; $\mathrm{RET}=$ retractor muscle; $\mathrm{STP}=$ spinotrapezius muscle; $\mathrm{LD}=$ latissimus dorsi muscle; $\mathrm{TM}=$ teres major muscle; 1 = thoracodorsal artery and vein; 2 = lumbodorsal branch; 3 = posterior auricular artery; $4=$ feed arteries and collecting veins; 5 = 'deep' thoracodorsal branch; 6 = 'superficial' thoracodorsal branch; $7=$ dual 'main' thoracodorsal vein; $8=$ spinotrapezius branch of the thoracodorsal artery.

and connective tissue that covered the transition point of the feed arteries and collecting veins into the thoracodorsal vessels were removed to optimize visibility.

The number and routing of feed arteries and collecting veins of the RET were documented in 26 animals. All side branches of vessels that supplied other muscles were ligated and cut until the RET was connected to the body exclusively by the thoracodorsal pedicle. As the diameters of the thoracodorsal vessels were too small for performing microsurgical anastomoses, the vascular pedicle running between the latissimus dorsi (LM) and teres major (TM) muscles (see fig. 1a), was dissected further upstream until a suitable vessel diameter $(\sim 0.3 \mathrm{~mm})$ was reached. Both the anatomically difficult accessible location within the armpit and the density of side branches make the axillary vessels unfit as an alternative to the smaller thoracodorsal vessels.

Surgical procedures typically required $\sim 5 \mathrm{~h}$. At the end of the study, preparation time had decreased towards $4 \mathrm{~h}$.

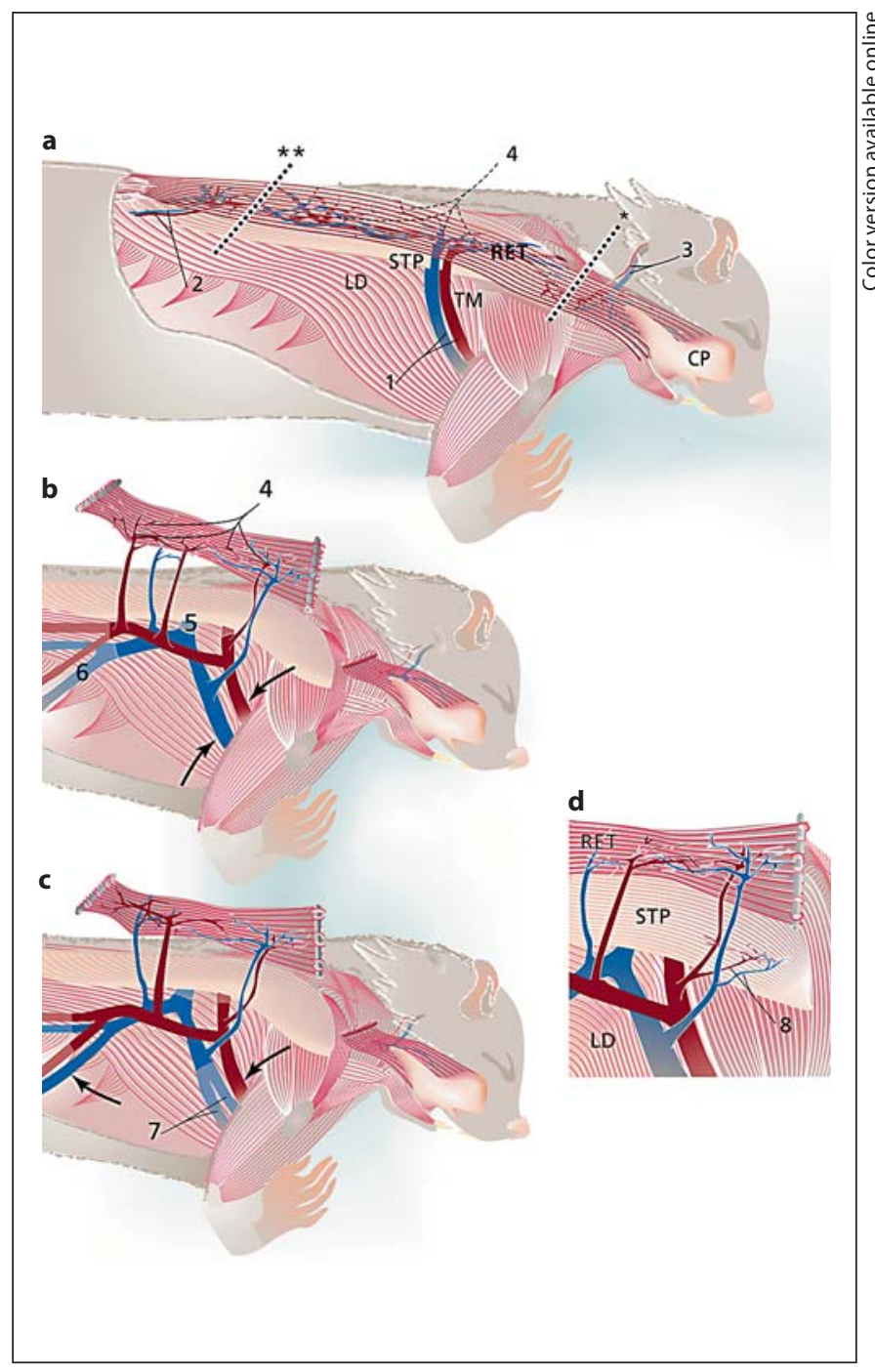

Vascular Territory

In contrast to previous I-R experiments [14], the entire RET was used in this study. Therefore, in 8 of 26 preparations the vascular territory supplied by the feed arteries of the RET was investigated by intravascular injection with plastic as described [19, 20]. Briefly, 12 parts of Araldite $\mathrm{F}^{\circledR}$ with $7.5 \%$ Microlith-T pigment was mixed with 4 parts of diluent DY 026 SP and 9 parts of hardener HY 2967 (all from Ciba-Geigy BV, Arnhem, The Netherlands). At the end of the dissection, the thoracodorsal artery was ligated as far proximally as possible. Following arteriotomy, a cannula (outer diameter $\sim 0.25 \mathrm{~mm}$ ) was inserted and secured to the vessel with two ligatures. Vessels were flushed with $1 \mathrm{ml}$ of Fraxiparine $^{\circledR}(\sim 100$ units; GlaxoSmithKline, Zeist, The Netherlands) to prevent clotting. After that, the hamster was killed as described above and the Araldite $\mathrm{F}^{\circledR}$ mixture was injected through the cannula at a perfusion pressure of $210 \mathrm{~mm} \mathrm{Hg}$. The relatively high injection pressure was required because of the small diameter of the cannula. By a closed valve, the vasculature was main- 

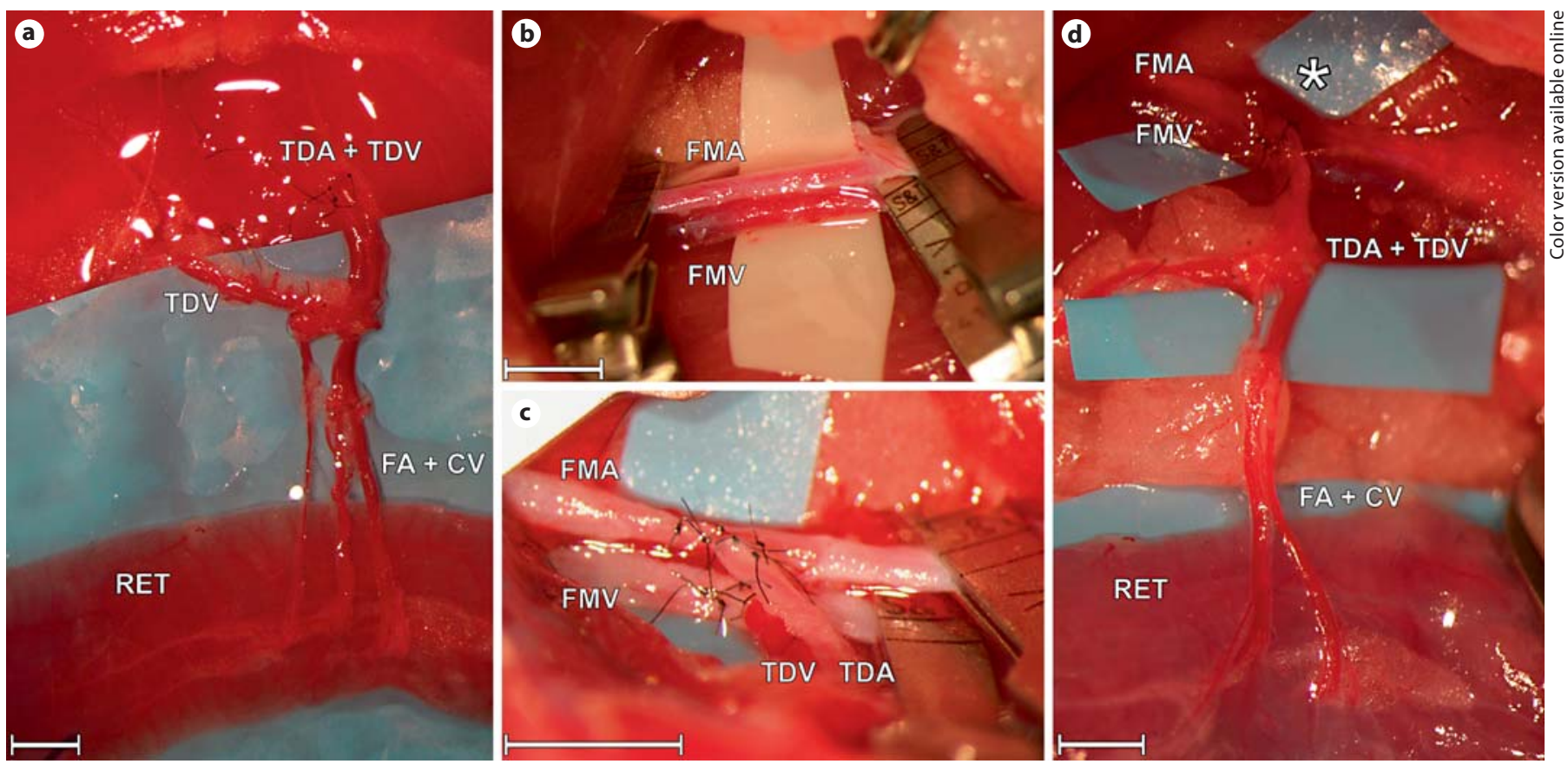

Fig. 2. Transplantation procedure of the RET muscle. a The RET is isolated on its thoracodorsal pedicle (TDA + TDV). Note that the 'superficial' venous branch (TDV) is also dissected free and available for anastomosis. $\mathbf{b}$ The femoral artery and vein (FMA + FMV) are dissected free to create the acceptor site. c End-to-side anastomoses are performed between thoracodorsal and femoral vessels. d Microvascular clamps are in situ. Successful restoration of blood flow following release of the microvascular clamps. The asterisk indicates the microvascular anastomoses. RET $=$ Retractor muscle; $\mathrm{FA}=$ feed arteries; $\mathrm{CV}=$ collecting veins; $\mathrm{TDA}=$ thoracodorsal artery; TDV $=$ thoracodorsal vein; FMA = femoral artery; FMV = femoral vein. Pieces of blue (a, c, d) and white (b) surgical gloves were used to enhance tissue contrast during surgery. The scale bars represent $2 \mathrm{~mm}$. tained under constant pressure overnight in order to allow the plastic to polymerize. Subsequently, the muscle flap was removed from the hamster. The flap was then suspended in graded concentrations of ethanol (50\%-70\%-80\%-96\%-absolute; incrementing every $24 \mathrm{~h}$ ) and then in methyl benzoate (Sigma-Aldrich Chemie $\mathrm{BV}$, Zwijndrecht, The Netherlands) to clear the muscle tissue. The entire preparation was examined under a microscope (Makroskop M420; Wild, Heerbrugg, Switzerland) to distinguish the vascular territory containing Araldite $\mathrm{F}^{\circledR}$. Photomicrographs were taken (E450 camera; Nikon, Tokyo, Japan; total magnification $\times 10$ ) and the total muscle length as well as that of border areas at each end of the muscle that were not filled with Araldite $\mathrm{F}^{\circledR}$ were measured to the closest millimeter. To normalize the size of unfilled border areas across preparations with different absolute lengths, the length of unfilled areas was expressed as percentage of the respective total muscle length.

\section{Allograft Muscle Transplantation}

In a pilot study for allograft transplantation $(n=2)$, the right RET flap was isolated in donor hamsters as described above (see fig. 2a). The thoracodorsal artery and vein were cut obliquely in order to increase vascular diameter and thus facilitate the subsequent procedure for performing anastomoses. Volume-controlled flush of the vascular bed was performed with $1 \mathrm{ml}$ warmed Ringer's lactate solution containing 100 units of Fraxiparine ${ }^{\circledR}$, using a $\sim 0.15$-mm cannula inserted into the thoracodorsal artery $(\sim 0.1 \mathrm{ml} / \mathrm{min})$. The washout fluid was heparinized, because this has been shown to increase ischemic tolerance in free flaps [21-23]. The tissue was kept moist by continuous irrigation with preheated Ringer's lactate solution. During the same period of surgery, an oblique incision was made through the skin overlying the left inguinal region of a recipient hamster anesthetized as described above. The femoral artery and vein were dissected free from connective tissue to create a suitable acceptor site for the muscle flap, as shown in figure $2 \mathrm{~b}$. The femoral vessels were clamped using microvascular clamps (S\&T AG, Neuhausen, Switzerland). Arteriotomy and venotomy were performed with microscissors. The RET free flap from the donor hamster was transferred to the recipient hamster and blood supply was re-established by end-to-side microanastomosis of the donor thoracodorsal artery and vein to the recipient femoral artery and vein (see fig. 2c, d). The end-to-side method was preferred because of the significant size discrepancy between the donor and recipient vessels [24]. Four to five 11-0 sutures (Ethicon; Johnson \& Johnson, Amersfoort, The Netherlands) were used for each microanastomosis. Immediately and during $1 \mathrm{~h}$ of reperfusion, anastomotic patency was tested using visual inspection of muscle color and vessel shape. Besides, the 'milking test' was performed [25, 26]. In short, a Dumont No. 5 microforceps was used to occlude the lumen of the thoracodorsal artery approximately $2 \mathrm{~mm}$ 
Fig. 3. Distribution of number of feed arteries and collecting veins in individual hamster RET. For all 26 muscles studied the distribution of the number of feed arteries and collecting veins is depicted. Overall, there are two or three (88\%) feed arteries vs. two (73\%) collecting veins.
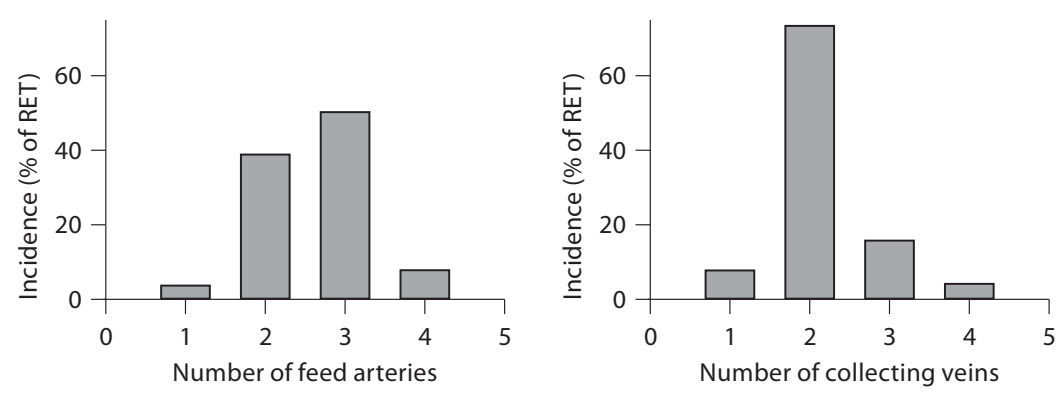

downstream from the anastomosis. A second forceps was moved downward from the occluding forceps to clear a $\sim 2 \mathrm{~mm}$ vascular segment from blood. Anastomotic patency was confirmed by immediate anterograde refilling after removal of the most proximal (first) forceps.

\section{Data Presentation}

Representative illustrations were prepared to describe the vascular supply to the RET. Summary data are reported as the percentage of hamsters (out of $n=26$ ) which exhibited the designated number of feed arteries or collecting veins. Photomicrographs were taken to illustrate the vascular anastomoses prepared surgically and to demonstrate the perfused vascular territory.

\section{Results}

\section{Isolation of the Retractor Muscle}

The average resting length of the RET muscle measured from cheek pouch to lumbodorsal fascia was $36 \pm$ $1 \mathrm{~mm}(\mathrm{n}=26)$. Muscles typically shortened by $20-30 \%$ when cut, as reported previously [8].

\section{Vascular Isolation}

The blood supply to the RET enters via several routes (fig. 1a). The feed arteries, which branch off from the thoracodorsal artery to enter the ventral surface of the muscle, provide the main blood supply of the RET. In addition, the posterior auricular artery, a branch of the external carotid artery, gives off the anterior RET artery, which enters the muscle at the level of the scapula and vascularizes the rostral region of the RET $[1,4,7]$. An additional small perforating artery was found to supply the lumbodorsal (i.e. caudal) region of the muscle (fig. 1a). These vessels supplying the rostral and caudal regions were cut in order to clearly visualize the ventral surface of the RET.

\section{Anatomical Variation in Arterial Supply}

The branches of the thoracodorsal artery which form the RET feed arteries were found to have both consistent and variable anatomical patterns (fig. $1 \mathrm{~b}, \mathrm{c}$ ). In all preparations $(n=26)$ the main thoracodorsal artery bifurcated into two major branches. The first, 'deep branch' ran underneath the spinotrapezius muscle; the other, 'superficial branch', ran over the latissimus dorsi muscle, and consistently bifurcated into one branch supplying the latissimus dorsi muscle while the other branch supplied the overlying skin. The length of the main thoracodorsal pedicle before the bifurcation was approximately $5 \mathrm{~mm}$. The total length of the vascular pedicle to the muscle border varied from $\sim 13 \mathrm{~mm}$ at the side of the most rostral feed artery to $\sim 25 \mathrm{~mm}$ at the location of the most caudal feed artery.

Across preparations $(n=26)$, the number of feed arteries varied from one to four, with their distribution displayed in figure 3. Generally, three (50\%; fig. 1b) or two (38\%; fig. 1c) feed arteries supplied the RET. With one exception, all RET had at least one feed artery that branched off before the first bifurcation or from the 'deep branch' (96\%) itself. The remaining feed arteries originate from the 'superficial branch'. A solitary feed artery, i.e. without paired collecting vein, was found in many preparations (42\%).

In order to isolate the RET on the thoracodorsal vessels, a variable pattern of smaller vessel branches to surrounding muscles and fat pads needed to be ligated and cut. For the 'deep branch' this was done distal from the point where the feed arteries originate from the thoracodorsal artery. While this was difficult due to lack of space, it was simplified by making an incision in the spinotrapezius muscle (STP, fig. 1a). The diameter of the main thoracodorsal artery was $\sim 0.3 \mathrm{~mm}$ in the region used for creating anastomoses. Although the more proximal arterial segments were larger, they did not offer a 


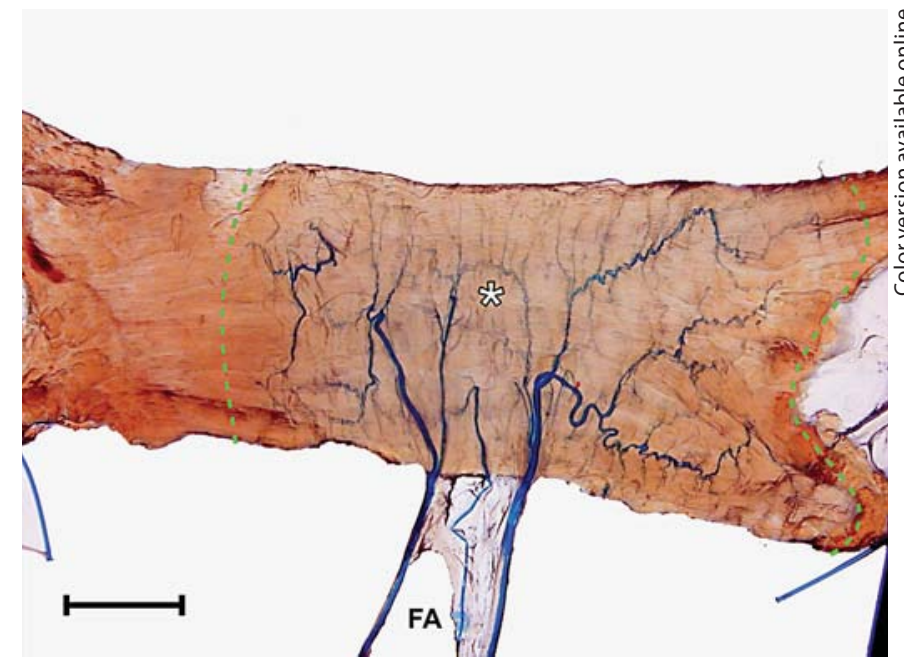

Fig. 4. Photomicrograph of the RET muscle flap after injection of Araldite $\mathrm{F}^{\circledR}$ into the thoracodorsal artery. The rostral muscle end is oriented to the right. This representative photomicrograph of vascular filling with Araldite $\mathrm{F}^{\circledR}$ illustrates that the RET is primarily vascularized by three branches (which form the feed arteries (FA)) arising from the thoracodorsal artery. The muscle border at the cranial end was almost completely perfused, whereas $21 \%$ of muscle length bordering the caudal end was not. Fragments of dark sutures (blue in the online version), that connect the muscle ends to stainless steel wires, are visible on both lateral sides of the photograph. Dotted lines (green in the online version) represent the borderlines of the non-perfused regions. Note the presence of multiple arcading anastomoses between distinct feed arteries at arteriolar level, indicated by an asterisk. The scale bar represents $3 \mathrm{~mm}$. FA $=$ Feed arteries

better alternative for microsurgical anastomosis because of their many side branches.

\section{Anatomical Variation in Venous Drainage}

Distinct types of venous patterns were identified (fig. 1b, c). Similar to the anatomy of the arterial supply, the main thoracodorsal vein consistently $(n=26)$ bifurcated into 'deep' and 'superficial' thoracodorsal branches which received blood from the collecting veins draining the RET. In all but 2 cases, at least one collecting vein drained into the main or into the 'deep' thoracodorsal vein while in the other 2 preparations all collecting veins drained into the 'superficial' thoracodorsal vein.

In 8 preparations $(31 \%)$ the main thoracodorsal vein was dual over its entire course between the latissimus dorsi and teres major muscles (see fig. 1c). In all 8 cases, these twin veins converged just before reaching the most rostral collecting vein of the RET and then bifurcated into the 'deep' and 'superficial' vein. When dual main thoracodor- sal veins were present, they appeared smaller as compared to preparations having a single thoracodorsal vein of $\sim 0.3$ $\mathrm{mm}$ diameter. However, in such cases the 'superficial' vein, which has a similar diameter, provides a suitable alternative for performing a vascular anastomosis (see fig. 1c).

The distribution of the number of collecting veins in individual RET muscles is depicted in figure 3. Across hamsters $(n=26)$, the number of collecting veins varied from one to four, with two present in most (73\%) cases. In 15 preparations (57\%), all feed arteries had paired collecting veins and their routing was identical. As seen with small arterial branches, a variable pattern of small venous branches to surrounding muscles and fat pads were ligated and cut to prepare a free flap that was isolated to the thoracodorsal artery and vein. Branches running from the spinotrapezius muscle often drained in the most proximal collecting vein (69\%).

\section{Vascular Territory}

Following injection with Araldite $\mathrm{F}^{\circledR}$ via the thoracodorsal artery $(n=8)$, the vascular bed of the RET was nearly completely stained except for the lumbodorsal and anterior borders (17 \pm 3 and $6 \pm 3 \%$ of total muscle length, respectively). Figure 4 shows a representative example.

\section{Allograft Transplantation}

In a pilot study, we examined whether the RET, with preserved feed arteries and collecting veins, could be isolated on the thoracodorsal pedicle for use as a free flap model in future studies. Thus, two transplantations of the RET from a donor hamster to the femoral artery and vein of a recipient hamster were performed as described in Materials and Methods. The duration of ischemia during these transplantations was $\sim 50 \mathrm{~min}$. Both of the two transplantations that were performed were considered successful, as confirmed visually through the microscope. Observations immediately after restoration of blood flow included true filling of the vascular system by change of muscle color from grey-blue to pink-red and natural rounded appearances of the thoracodorsal and recipient femoral veins. Besides, microvascular patency was verified by a positive milking test throughout the 1-hour testing period.

\section{Discussion}

The goal of this study was to determine whether the RET muscle of the hamster cheek pouch could be utilized as a model for studying the effects of transplantation 
on the microcirculation of mammalian skeletal muscle. Complete surgical isolation of the RET and its vessels was performed, such that only the primary arterial supply and venous drainage remained attached to the muscle. Measurement of the perfused vascular territory of free muscle flaps following Araldite $\mathrm{F}^{\circledR}$ injection showed that, after transplantation, the muscle is adequately perfused via feed arteries and veins arising from the thoracodorsal vessels, which function as the donor vessels. Further, the results of this study verify that the caliber of the proximal section of the thoracodorsal artery and vein is suitable for microvascular anastomosis at a suitable location, e.g. the femoral artery and vein.

As shown by injection with Araldite $\mathrm{F}^{\circledR}$, relatively small regions of the caudal and the rostral borders of the RET may be excluded from the free flap preparation, as blood flow is unlikely to be restored in these areas following transplantation. The finding that respective end-regions are no longer perfused once the RET is cut from its origin and insertion is in agreement with our observation that, in addition to the feed arteries that branch off the thoracodorsal artery, there were two other sites of vascularization at respective muscle borders. Whereas the perforating lumbodorsal arterial branch at the caudal end has not been described in detail previously, vascularization of the rostral region of the RET has been well defined [7]. Within the muscle, the anterior RET artery and (to a lesser extent) the saccular arteries of the cheek pouch are interconnected to the posterior RET 'feed' arteries by several anastomoses at arteriolar level. The presence of these anastomoses suggests that, with time, the vascular supply to each end of the muscle may be re-established through remodeling of the microcirculation to restore blood flow into ischemic regions. For experiments designed to measure the force developed by RET muscle fibers during contractions, these non-perfused border areas at each end are used to secure the muscle to an experimental platform while observing the microcirculation with intravital microscopy $[5,9,14]$.

Apart from a somewhat variable number of feed arteries and collecting veins, we found the gross vascular anatomy to be relatively consistent across preparations. These findings are consistent with an earlier study of blood vessels to the rat cremaster muscle [27]. For RET with unequal numbers of arteries and veins, it should be noted that solitary feed arteries can provide an advantage for experimental observations in that these vessels are more easily visualized for intravital microscopy as compared to arteries that run parallel to (and can thereby be obscured by) a paired collecting vein. The venous anatomy of the
RET can be complicated by the presence of dual main thoracodorsal veins that are too small for effective surgical manipulations. Nevertheless, in such cases we found that the more caudal 'superficial' thoracodorsal vein provides a viable alternative of sufficient diameter. Moreover, the vascular pedicle of the RET is consistently of sufficient length to perform microsurgical anastomoses.

The use of the RET as a model for free flap transplantation has several restrictions. Firstly, the diameters of the donor artery and vein measure $\sim 0.3 \mathrm{~mm}$. This dimension is considered to be near the smallest vessel size that can be surgically attached to another one [18]. As anastomotic patency decreases with diameter, such a challenging technical procedure is recommended to be performed by a highly experienced microsurgeon. Secondly, due to the small size of the vascular branches, and the complexity of their relationship with each other, dissection of the pedicle to the RET requires extreme care and patience. Ligating all of the side branches can also cause damage to the feeding and draining vessels. With practice, however, dissection of the RET as a vascularized free flap can be readily performed in a reproducible manner.

Contrary to the sole parameter (survival) that can be measured in the majority of free flap animal models [for examples, see 28], only few adequate animal skeletal muscle models exist that allow detailed intravital microcirculatory analysis. The primary reason for developing the hamster RET free flap model was that both contractile muscle [17] and microcirculatory measurements [15] can be used to evaluate the efficacy of preservation techniques in future studies. For example, the potential for recovery of muscle function after cold ischemia depends on recovery of both the parenchymal (muscle) cells and their vascular supply $[16,29]$. The use of intravital microscopy allows for direct visualization of the microvascular network within the RET along with its feed arteries [5, 9], including manifestations of impaired endothelial cell function and vasomotor control $[3,14]$ or leukocyte/endothelial interactions [14, 30, 31]. An important advantage of the RET over other muscle preparations used to study the microcirculation, such as the free vascularized rat or mouse cremaster muscle models $[15,32]$, is that the parallel arrangement of the RET muscle fibers enables a quantitative and reliable serial evaluation of the contractile function of the muscle fibers $[5,9,14]$.

In terms of clinical relevance, the RET model has the potential to augment our understanding of microvascular and skeletal muscle dysfunction following ischemic insults of various varieties. Currently, the clinical use of free tissue transfers shows relatively low failure rates of 
$5-6 \%[33,34]$. The failure rate in replantations is much higher (8-18\% [33]). Apart from complete graft loss, the number of partial failures is not often reported and probably underestimated [35]. The main reasons for total flap failure remain thrombosis of the anastomosis [34] and vasospasm [36, 37]. Partial flap failure, however, is mainly initiated by local ischemia in hypoperfused areas. The latter is often referred to as the no-reflow phenomenon [for review, see 31]. Recently, it was reported that disturbance in active vasomotility is a major factor in development of the no-reflow phenomenon in free flaps following I-R [38]. Most evidence for the role of endothelial vasomotor dysfunction however results from animal studies in particular in cardiac muscle tissue [39]. We previously concluded that following I-R ascending vasodilation in the RET feed arteries was diminished due to impairment of local response to the vasodilatory trigger distally in the vascular tree of the muscle [14]. We hypothesize that interventions that lead to re-establishment of local vasodilator signals will contribute to prevention of hypoperfusion and the no-reflow phenomenon. Interventions that could be employed in future research include cold preservation and several pharmacological approaches [17].

Anticipating on future experiments with the RET model, including cold ischemic events and subsequent reperfusion, it must be emphasized that success percentages of $\sim 90 \%$ have been reported in microanastomoses with similar diameters $(0.3-0.4 \mathrm{~mm})$ following $24 \mathrm{~h}$ of storage at $4^{\circ} \mathrm{C}[40]$. Therefore, we expect that irrespective of temperature, the RET can be used reliably with gentle tissue handling, good visualization and the meticulous use of fine instruments. Given the anatomical complexity and technical constraints of the surgical preparation, the verification of reperfusion was in the present study limited to visual inspection and the milking test. In future RET transplantation experiments, vascular integrity will be assessed by direct observation of the microvascu- lar network through intravital microscopy, enabling quantification of reperfusion by blood flow measurement [41]. Functional parameters could then include evaluation of diameter changes during ascending vasodilation and skeletal muscle twitch and tetanus tensions [14]. For such an investigation, inbred hamster strains need to be used, since it is not possible to reliably study the sole effect of prolonged reperfusion of the RET flap in genetically non-identical animals, as earlier reports from limb allotransplantations show microcirculatory changes within $24 \mathrm{~h}$ after transplantation [42]. An additional advantage of the RET transplantation model is that it has the potential to display allograft-related immunological responses in survival studies on outbred strains.

In conclusion, the present findings provide essential new anatomic information concerning the hamster RET muscle and its vascular pedicle in light of using this preparation as a model to study the microcirculation and contractile muscle function in free muscle flap transplantation. We demonstrate the relative consistency of its vascular anatomy while accounting for subtle variations in arterial and venous branches. Moreover, in a pilot study, we showed that the RET can be prepared as a viable allograft.

\section{Acknowledgements}

The authors thank Ingrid Janssen for skillfully producing the illustrations in Adobe Illustrator CS and Quinten Ruhé, MD, $\mathrm{PhD}$, for optimizing the graphical quality of the photomicrographs. Willem van Wolferen and Simon Plomp are gratefully acknowledged for their technical assistance during the Araldite $\mathrm{F}^{\circledR}$ study. This study was supported by the Jan Dekker and Ludgardine Bouwman Foundation, The Netherlands. Steven Segal, $\mathrm{PhD}$, is supported by NIH grants RO1-HL41026 and RO1HL56786. The authors do not have any financial interests in products, devices and drugs used in this study.

\section{References}

1 Priddy RP, Brodie AF: Facial musculature, nerves and blood vessels of the hamster in relation to the cheek pouch. J Morphol 1948; 83:149-180

2 Swain DP, Pittman RN: Oxygen exchange in the microcirculation of hamster retractor muscle. Am J Physiol 1989;256:H247-H255.

-3 Segal SS, Jacobs TL: Role for endothelial cell conduction in ascending vasodilatation and exercise hyperaemia in hamster skeletal muscle. J Physiol 2001;536:937-946.
4 Sullivan SM, Pittman RN: Hamster retractor muscle: a new preparation for intravital microscopy. Microvasc Res 1982;23:329-335.

$\checkmark 5$ VanTeeffelen JW, Segal SS: Interaction between sympathetic nerve activation and muscle fibre contraction in resistance vessels of hamster retractor muscle. J Physiol 2003; 550:563-574.

-6 Grasby DJ, Morris JL, Segal SS: Heterogeneity of vascular innervation in hamster cheek pouch and retractor muscle. J Vasc Res 1999; 36:465-476.
7 Poor E, Lutz BR: Functional anastomotic vessels of the cheek pouch of the hamster (Mesocricetus auratus). Anat Rec 1958;132: 121-126.

-8 Nakao M, Segal SS: Muscle length alters geometry of arterioles and venules in hamster retractor. Am J Physiol 1995;268:H336$\mathrm{H} 344$.

-9 Welsh DG, Segal SS: Coactivation of resistance vessels and muscle fibers with acetylcholine release from motor nerves. Am J Physiol 1997;273:H156-H163. de With/de Vries/Kroese/ van der Heijden/Bleys/Segal/Kon 
10 Segal SS: Integration of blood flow control to skeletal muscle: key role of feed arteries. Acta Physiol Scand 2000;168:511-518.

11 Segal SS: Regulation of blood flow in the microcirculation. Microcirculation 2005; 12: 33-45.

12 Christensen KL, Mulvany MJ: Location of resistance arteries. J Vasc Res 2001;38:1-12.

-13 Emerson GG, Segal SS: Endothelial cell pathway for conduction of hyperpolarization and vasodilation along hamster feed artery. Circ Res 2000;86:94-100.

$\checkmark 14$ De With MC, Haug SJ, van der Heijden EP, Segal SS: Ischemia-reperfusion impairs ascending vasodilation in feed arteries of hamster skeletal muscle. Microcirculation 2005; 12:551-561.

-15 Bastiaanse J, Nanhekhan LV, SlaafW, Boeckx WD, Oude Egbrink MG: Preservation of rat cremaster muscle microcirculation after prolonged cold storage and transplantation. J Surg Res 2006;131:41-48.

16 Corner JA, Berwanger CS, Stansby G: Preservation of vascular tissue under hypothermic conditions. J Surg Res 2003;113:21-25.

17 Van der Heijden EP, Kroese AB, Werker PM, de With MC, de Smet M, Kon M, Bar DP: Improving the preservation of isolated rat skeletal muscles stored for $16 \mathrm{~h}$ at $4^{\circ} \mathrm{C}$. Transplantation 2000;69:1310-1322.

18 Huang CD, Chow SP, Chan CW: Experience with anastomoses of arteries approximately $0.20 \mathrm{~mm}$ in external diameter. Plast Reconstr Surg 1982;69:299-305.

19 Van der Heijden EP, Kroese AB, Werker PM, Kon M, de With MC, Bar DP: Preservation of rat skeletal muscle function during storage for $16 \mathrm{~h}$ at $4^{\circ} \mathrm{C}$ is not improved by pre-storage perfusion. Clin Sci (Lond) 2003;105:29-37.

20 Van der Zwan A, Hillen B: Araldite $\mathrm{F}^{\circledR}$ as injection material for quantitative morphology of cerebral vascularization. Anat Rec 1990; 228:230-236

21 Calhoun KH, Tan L, Seikaly H: An integrated theory of the no-reflow phenomenon and the beneficial effect of vascular washout on no-reflow. Laryngoscope 1999;109:528-535.
22 Pantazi G, Knight KR, Romeo R, Hurley JV, Hennessy O, Willemart G, Penington AJ, Morrison WA: The beneficial effect of heparin in preischemic perfusion solutions for cold-stored skin flaps. Ann Plast Surg 2000 44:304-310.

23 Rosen HM, Slivjak MJ, McBrearty FX: Preischemic flap washout and its effect on the no-reflow phenomenon. Plast Reconstr Surg 1985;76:737-747.

24 Al Sukhun J, Lindqvist C, Ashammakhi N, Penttila H: Microvascular stress analysis. I. Simulation of microvascular anastomoses using finite element analysis. Br J Oral Maxillofac Surg 2007;45:130-137.

25 Pignatti M, Benati D, Cavadas PC: Effect of the two-wall-stitch mistake upon patency of rat femoral vein anastomosis: preliminary observations. Microsurgery 2004;24:339344.

26 Wei FC, Suominen S: Principles and techniques of microvascular surgery; in Mathes SJ (ed): Plastic Surgery. Part 1. Philadelphia, Elsevier, 2006, pp 507-538.

27 Meininger GA, Fehr KL, Yates MB: Anatomic and hemodynamic characteristics of the blood vessels feeding the cremaster skeletal muscle in the rat. Microvasc Res 1987;33:8197.

28 Zhang F, Sones WD, Lineaweaver WC: Microsurgical flap models in the rat. J Reconstr Microsurg 2001;17:211-221.

29 Fuller BJ: Storage of cells and tissues at hypothermia for clinical use. Symp Soc Exp Biol 1987;41:341-362.

30 Gudemez E, Turegun M, Zins J, Siemionow M: Microvascular permeability following composite tissue transplantation. Ann Plast Surg 1998;41:519-529.

31 Urbaniak JR, Seaber AV, Chen LE: Assessment of ischemia and reperfusion injury. Clin Orthop Relat Res 1997;30-36.

32 Ozer K, Zielinski M, Unsal M, Siemionow M: Development of mouse cremaster transplantation model for intravital microscopic evaluation. Microcirculation 2002;9:487-495.
33 Salemark L: International survey of current microvascular practices in free tissue transfer and replantation surgery. Microsurgery 1991;12:308-311.

34 Wolff KD, Holzle F, Wysluch A, Mucke T, Kesting M: Incidence and time of intraoperative vascular complications in head and neck microsurgery. Microsurgery 2008;28: 143-146.

35 Weinzweig N, Gonzalez M: Free tissue failure is not an all-or-none phenomenon. Plast Reconstr Surg 1995;96:648-660.

36 Baccarani A, Yasui K, Olbrich KC, El Sabbagh A, Kovach S, Follmar KE, Erdmann D, Levin LS, Stamler JS, Klitzman B, Zenn MR: Efficacy of ethyl nitrite in reversing surgical vasospasm. J Reconstr Microsurg 2007;23: 257-262.

-37 Jokuszies A, Niederbichler A, Meyer-Marcotty M, Lahoda LU, Reimers K, Vogt PM: Influence of transendothelial mechanisms on microcirculation: consequences for reperfusion injury after free flap transfer. Previous, current, and future aspects. J Reconstr Microsurg 2006;22:513-518.

38 Nanobashvili J, Neumayer C, Fuegl A, Blumer R, Prager M, Sporn E, Polterauer P, Malinski T, Huk I: Development of 'no-reflow' phenomenon in ischemia/reperfusion injury: failure of active vasomotility and not simply passive vasoconstriction. Eur Surg Res 2003;35:417-424.

-39 He GW: Endothelial function related to vascular tone in cardiac surgery. Heart Lung Circ 2005; 14:13-18.

40 Chaopricha W, Chen LE, Seaber AV, Bossen E, Urbaniak JR: Micro-anastomosis of 0.3$0.4 \mathrm{~mm}$ vessels after cold ischemia using a rat model of toe-to-thumb transplantation. Microsurgery 1993;14:619-623.

41 Jacobs TL, Segal SS: Attenuation of vasodilatation with skeletal muscle fatigue in hamster retractor. J Physiol 2000;524:929-941.

-42 Ozer K, Adanali G, Zins J, Siemionow M: In vivo microscopic assessment of cremasteric microcirculation during hindlimb allograft rejection in rats. Plast Reconstr Surg 1999; 103:1949-1956 